\title{
CEREMONIAS DEL CONSENSO Y LA CONTRACULTURA: ANTONI MIRALDA O LA INVERSIÓN CARNAVALESCA
}

\author{
IÑAKI ESTELla NORIEGA ${ }^{1}$ \\ Universidad Complutense de Madrid
}

\begin{abstract}
El arte de acción ha tenido desigual fortuna en España, tanto en lo que se refiere a la práctica artística como a su estudio por parte de la historia del arte. Entendido como expresión liberadora y progresista por la crítica coetánea, y, por tanto, ajeno a los parámetros culturales de la dictadura, en este artículo proponemos volver al archivo para problematizar dicha comprensión y valoración crítica de los modos de interpretación y aceptación. Nuestro estudio se centra en el happening y su desarrollo en la década de los sesenta y setenta del siglo XX en España a través de la relevancia de algunos eventos que no han pasado al archivo (la importancia de Granollers, la participación de Dalí, p.e.), centrándonos en las acciones de Antoni Miralda donde se desvelan culturas de consenso y arraigo que cuestionan las interpretaciones historiográficas dadas.
\end{abstract}

Palabras clave: arte de acción, happening, giro performativo, contracultura, historiografía, Salvador Dalí, Antoni Miralda.

\section{CEREMONIES OF CONSENSUS AND COUNTERCULTURE:}

ANTONI MIRALDA AND CARNIVAL INVERSION

Performance art in Spain, both as an art practice and as a subject of scholarly study, has traditionally been varyingly understood. Taken as a token for freedom and resistance politics by critics opposed to the cultural parameters imposed by the dictatorship, in this article the author proposes a revision of the archive with the aim of problematizing such understanding and critical comprehension. This study concentrates on happenings and their development during the sixties and seventies in Spain that have gone unnoticed in historical research (i.e. the importance of Granollers, Dalís participation in some happenings), with emphasis on the works of Antoni Miralda which deal with the culture of consensus and traditions that challenge other firmly established interpretations.

Key words: performance art; happenings; performative turn; Spanish counterculture; historiography; Salvador Dalí; Antoni Miralda.

Cómo citar este artículo / Citation: Estella Noriega, Iñaki (2019): "Ceremonias del consenso y la contracultura: Antoni Miralda o la inversión carnavalesca”. En: Archivo Español de Arte, vol. 92, núm. 367, Madrid, pp. 319-332. https://doi.org/10.3989/aearte.2019.21.

En los últimos años se ha visto una proliferación de publicaciones que han abordado desde diferentes perspectivas el arte de acción permitiendo la apertura de un dinámico debate. De entre gran parte de las publicaciones destaca cierta inercia a considerar el arte de acción como intrínsecamente poseedora de un sentido político o resistente que actualiza el espíritu de la vanguardia o va en paralelo a la contracultura. Esta idea es notable en el caso de las obras que se desarrollaron en las décadas de los sesenta y setenta, décadas que en España vieron la eclosión y trans-

1 iestella@ucm.es / ORCID iD: http://orcid.org/0000-0002-7373-3243. 
formación de las diferentes artes de acción. Un caso reciente es Maite Garbayo cuyo libro sobre el performance en el tardofranquismo asume cómo estas obras implicaron una "estrategia estética (que) se puede convertir en un espacio de resistencia"2; en efecto, si alude a una posibilidad aún está por publicarse el texto que desborde esa posibilidad.

La reescritura del arte de acción español de las décadas de los 60 y 70 está hoy cobijada por el apriorismo de su carácter resistente que se ha impuesto desde al menos inicios del milenio cuando ciertas artes performativas se recuperaron como origen de las prácticas activistas antiglobalización ${ }^{3}$. Los pocos autores que han retado esta perspectiva heroica han tenido que abordar el arte de acción de otras décadas, por ejemplo, los ochenta y noventa, para aportar enfoques renovados ${ }^{4}$. El resultado hoy es la aceptación de un conjunto de obras de muy diversa índole cobijadas por una criticidad muy atenuada que impide la creación de un marco de comprensión que permita una interpretación más compleja del arte de performance.

En el presente estudio abordamos la incorporación del happening en España atendiendo al trabajo realizado hasta finales de los 70 por uno de sus artistas más relevantes, como es Antoni Miralda. Su trabajo se desarrolla hasta la actualidad cuando ha alcanzado reconocimiento máximo al recibir el Premio Velázquez en 2018. Con dicho ejercicio pretendemos problematizar la uniformidad bibliográfica ya señalada al evidenciar cómo algunas de las ideas presentes en su obra cuestionan la noción de resistencia que se le supone al medio. Nuestro objetivo último reside en despertar nuevos posicionamientos que reabran el debate teniendo en cuenta que ahora se dan las condiciones para ello.

\section{El arte de acción en la historiografía contemporánea: volver al archivo}

A pesar de la repercusión que tuvo en su momento, el happening es uno de los conceptos menos afortunados de la historiografía española dedicada a los estudios performativos, quizás por ser un anglicismo que implica una jerarquía muy determinada en el proceso de adopción cultural. Mientras que performance, arte de acción y otros conceptos han sido encumbrados por la literatura crítica ${ }^{5}$, los happenings se han marginado a lo mejor también por no ofrecer marcadas diferencias con el arte de acción en general. El uso del concepto se revela hoy en cierta medida anacrónico a pesar de que atrajo el interés de críticos e historiadores de muy diversas procedencias. Dicho carácter obsoleto ofrece un terreno idóneo pues permite alejarnos de las siempre simplificadoras tentaciones definitorias que acompañan a las nuevas formas artísticas; del mismo modo, posibilita que rastreemos su irrupción en un contexto histórico, la España del final del franquismo.

La España de los sesenta y setenta, heredera del aislacionismo que afectó a la crítica artística, dependió en ocasiones de teorías foráneas para abordar el fenómeno del arte de acción. Los casos de Simón Marchán y Alexandre Cirici son especialmente relevantes al respecto. El primero trajo de sus diferentes estancias en Alemania todo un conjunto de lecturas que se materializaron en "Del arte objetual al arte de concepto", cuya primera edición de 1972 fue un verdadero éxito. A pesar de que dos años más tarde, con la segunda edición, Marchán incorporó una adenda sobre el caso español, el resultado constataba la adopción y aclimatación de las inercias críticas vigentes en Alemania (y también Norteamérica) a la historiografía española. Su libro introdujo el modelo más aceptado de comprensión del happening — el que va de Harold Rosenberg a Allan Kaprow y demás - convirtiéndose en el modo dominante de comprensión del fenómeno.

\footnotetext{
2 Garbayo, 2016: 32.

3 Marcelo Expósito (2004: 129) realizaba esta recuperación con conceptos como la república de los radicales. En el mismo volumen, Simón Marchán Fiz (2004: 143) recuerda el vínculo íntimo entre nuevos comportamientos y resistencia durante el tardo franquismo.

4 Jorge Luis Marzo (2015: 269-303) vincula el arte de acción de los 80 con el contexto experiencial de la postmodernidad y en contraposición con el experimentalismo que domina, según el autor, en décadas previas que no aborda.

${ }_{5}$ Claro reflejo de este aspecto es la aceptación internacional de los estudios de performance, hoy un acercamiento plenamente legitimado.
} 
El caso de Cirici es más particular ${ }^{6}$. Su exilio durante la guerra civil le permitió estudiar en Francia, entrando pronto en contacto con la crítica de vanguardia desarrollada en el ámbito internacional. Gran parte de su actividad como crítico consistió en aplicar los conceptos que había desarrollado la crítica extranjera a la actividad artística de Cataluña, como si una actualización de las herramientas de análisis y del lenguaje precipitara una modernización de la práctica artística acoplada a estándares europeos. Sus sucesivas aperturas a los planteamientos de los intelectuales y críticos italianos - recordemos la influencia en la revista Serra D'Or de la que Cirici fue miembro del consejo editor, de los semiólogos del Grupo 63, entre los cuales estaba Umberto Eco-y anglosajones permitió incorporar muchos conceptos que, después de la pronta muerte del crítico catalán, cayeron prácticamente en desuso. Estas influencias encuentran su mejor exponente en la obra del crítico del Nouveau Réalisme francés, Pierre Restany ${ }^{7}$, de quien adoptó el término nuevo realismo para adaptarlo al contexto valenciano y catalán ${ }^{8}$. La adopción de los planteamientos de Restany aportaba una genealogía diferente de la que provenía de Estados Unidos, ya que en Francia el recorrido hasta las artes de acción contemplaba otras referencias que iban de las actuaciones sobre el lienzo de Georges Mathieu a Yves Klein.

Un ejemplo ilustrativo de cómo estas influencias generaban un marco de comprensión específico de lo que ocurría en Cataluña es el grupo El Gallot formado, por Josep Llorenç, Llorenç Balsach, Lluís Vila, Joaquim Montserrat, Joan Bermúdez, Antoni Anglé, Alfons Borell y otros. Azuzados por Anglé, conocedor a través de Vladimir Slepian de la vanguardia gestualista francesa $^{9}$, salieron a la calle para realizar algunas acciones consistentes en tirar rollos de papel por el suelo y pintar sobre ellos, invitando al público - y a algún que otro gallo - a participar. Escenificadas en varios enclaves de Barcelona y Sabadell en $1960^{10}$, atrajeron la atención popular llegando incluso a los medios de masas a pesar de que su aparición en el No-Do fue prácticamente la última acción del grupo.

Las imágenes que se han conservado de estos eventos conjugan una combinación singular ${ }^{11}$ : desde la sesión de fotos de Hans Namuth para Life, donde se ve Jackson Pollock en acción, hasta la pintura industrial de Pinnot Gallizio, pasando por los gestos a lo Georges Mathieu o una fiesta de pueblo. Esta heterogénea mezcla resulta de gran utilidad para el estudio sobre el modo diferencial de aceptación del arte de acción en España y su extrema particularidad, a medio camino entre el folklore progresivo ${ }^{12}$ y la neovanguardia europea, algo que todavía no se ha evidenciando en el discurso general del arte español, a pesar de que Cirici dedicara unos párrafos en su L'art catalá contemporani (1970) a los Gallots donde eran contemplados bajo el prisma aportado por el nuevo realismo francés que conocía de Restany.

Las paradojas que generaban las dependencias del extranjero no pasaron inadvertidas para otros críticos, y este era el caso de Marchán para quien el aterrizaje de esas ideas en España - lo que él denominó "la práctica mimética respecto del exterior"13 - fue determinante en el cul-desac en el que - según él- acabaron los nuevos comportamientos artísticos a finales de los setenta. Sin embargo, a pesar de denunciar la fuerza de la crítica extranjera y su desencaje en el contexto español, Marchán también fue cautivo de las inercias que llegaban de fuera. Así, cuan-

\footnotetext{
${ }^{6}$ Lombao, 2015: 31-38.

7 Sellés, 2007: 54-60.

${ }^{8}$ Cirici, 1970: 293 y ss. Cirici, 1963: 37-39. Otro ejemplo lo encontramos en l'art pobre que tomaba del arte povera italiano. Cirici, 1970.

9 En París, Anglés realizó con Slepian varios eventos pictóricos en el espacio público, consecuencia a su vez de conversaciones con Mijaíl Larionov. Balsach, 2013: 21-23. También Balsach, 2001.

${ }^{10}$ Las actividades del grupo son escasas: el 14/VIII/1960 realizan una pintura pública en frente a la Academia de Bellas Artes de Sabadell, donde luego exponen las obras. El 21/IX/1960 realizan acciones similares en diversas calles de Barcelona: Urquinaona, Caspe, Galería Mirador y Plaza de Cataluña; esta última fue grabada para No-Do.

${ }^{11}$ Las imágenes se pueden encontrar en Balsach, 2013.

12 De Martino, 2008. Seguidor de Antonio Gramsci, De Martino fue uno de los más relevantes estudiosos del folklore italiano tras la segunda guerra mundial que abordó bajo el prisma hegemónico: la relación de lo folklórico con la cultura oficial, concluyó, era de oposición, de ahí su carácter contestatario.

13 Marchán, 1991: 44.
} 
do realizó un análisis de la entrada del arte pop americano en España, puso en evidencia los delirios de grandeza de cierta crítica local que comprendió lo que había ocurrido en España como un precedente de lo que era reconocido internacionalmente. El ejemplo que utilizó para demostrar esto fue exactamente la lectura que Cirici hizo sobre El Gallot donde el grupo era presentado incluso como predecesor de los happenings del propio Kaprow ${ }^{14}$. En consecuencia, si Marchán era capaz de advertir y denunciar la hegemonía de la geografía del arte, no se aventuró a aceptar una narrativa que invirtiese los recorridos tradicionales del centro a la periferia.

Todo lo expuesto, más allá de desvelar la complejidad del desarrollo del arte de acción y su narrativa historiográfica, ofrece un panorama de nuestro arte contemporáneo en general, y de las prácticas performativas en particular, donde se ve claramente la necesidad que se tenía de replicar aquí la escena artística extranjera como expresión de modernidad. Esta adecuación ha dominado el análisis de nuestro propio entorno ensombreciéndolo y, lejos de potenciar las diferencias propias, incidía en las afinidades para no devolver un mal reflejo de lo que se consideraba el arte contemporáneo legítimo.

\section{Entrar y salir de la insularidad}

Tan solo en fechas muy cercanas ha habido un intento de reconstruir la insularidad ${ }^{15}$ del arte español, atendiendo a referencias locales que van del valleinclainismo a la impronta de Gómez de la Serna. El ejercicio ${ }^{16}$, interrumpido antes de ver sus primeros frutos, da como resultado una historia que nada tiene que ver con el discurso internacional aceptado: el lugar que en éste tiene el Black Mountain College sería ocupado por el Club 49 en el que conciertos de jazz se mezclaban con actuaciones cercanas a performances; los happenings de Kaprow, por la magia con cartas de Joan Brossa y la tienda de Claes Oldenburg, por el envelat de pinturas del grupo Cuatremeró en las fiestas del Poble Nou de 1964.

Una historia tal reconocería nuestra especial adopción de las artes de acción, tan particularmente extrema que se ha revelado inabordable incluso en aquellas exposiciones que buscaban expandir la geografía global del arte de performance hasta sus últimas consecuencias. Tal fue el caso de Out of Actions: Between Performance and the Object (1949-1979) (MOCA, Los Ángeles, 1998), exposición que legitimaba el arte de acción producido en la periferia (Europa del Este, Japón y Latinoamérica, entre otras). Esta exposición supuso uno de los ejemplos más claros de la expansión de la geografía del arte cuyos resultados reforzaban el poder del centro que aún atesoraba su papel de constructor de un discurso basado, al igual que el entonces emergente mercado financiero, en la superación de las diferencias nacionales. Out of Actions excluía al arte español — no había ni un sólo representante - que no llegaba siquiera a entrar en el apéndice del relato que ponía en marcha. Esto lo relegaba a una posición ajena tanto al centro irradiador como a la exótica periferia tradicionalmente marginada pero cuya historia debe ser recuperada para construir el arte global. Tampoco las ventajas que este indeterminado lugar podría haber generado en la historiografía o crítica española no fueron aprovechadas. El discurso sobre el arte contemporáneo español, escrito a inicios de los ochenta, había reprimido toda deriva performativa, a lo que se sumó el olvido que el discurso emergente a finales de los noventa hizo de lo local, al estar inmerso en la traducción de la teoría anglosajona.

La necesidad de invertir el discurso transicional tuvo además consecuencias a finales de los noventa cuando se vio en el abrazo a las artes de acción la superación del dominio de la pintura.

${ }^{14}$ Marchán se refería a lo que Cirici escribió en L’art ctalán conteporani: "La realidad, incluso en Cataluña es más parca, aunque el aluvión, como después sucediera con el conceptualismo, no se dejara esperar, así como la osadía crítica para magnificar anécdotas. En efecto, ¿no es un tanto desmesurada una cronología comparada para documentar la avanzadilla del pop catalán respecto al internacional?, o ¿no resulta pintoresco, desde el entusiasmo vanguardista, reivindicar que Els Gallots de Sabadell descubre el happening antes que A. Kaprow?". Marchán, 1983: 363.

${ }_{15}$ Crespo, 1965: 36-37.

16 Romero, 2007: 46-51. 
Para el discurso de los noventa, Fuera de formato (Madrid, 1983), exposición que programó numerosas acciones realizadas en la Plaza de Colón, adquiría un papel crepuscular en los nuevos comportamientos artísticos que quedarían en estado de aletargamiento hasta su recuperación a finales del siglo XX. Lógicamente, en los ochenta hubo otro tipo de artes de acción, pero éste se encontraba lejos de las premisas de aquellos "nuevos comportamientos", por lo que ni si quiera fue tenido en cuenta por el discurso hasta épocas muy recientes ${ }^{17}$. En ese entramado se afianzó el vínculo entre arte de acción y resistencia, resultando en la homogeneización historiográfica de gran parte de las prácticas performativas que fueron contempladas como un bloque único.

Otra consecuencia de este proceder fue que desvaneció la dosis de negatividad que acompañó a la recepción del arte de acción en los setenta y, de nuevo Marchán y Cirici son referenciales en esta cuestión ya que este tipo de prácticas artísticas no se aceptaron sin rechistar. Por ejemplo, el primero veía con cierta precaución algunos de los happenings que se desarrollaban en forma de rituales ya que en ellos se podía vislumbrar la inercia hacia el espectáculo fascista de masas que desembocaba en la estetización de la política en la línea de Walter Benjamin ${ }^{18}$. La advertencia de Marchán resulta de interés ya que, a pesar de estar refiriéndose a algunos artistas internacionales (el accionismo vienés p.e.), su llamada de atención parecía aludir a obras en la línea de los ceremoniales que Antoni Miralda empezó a hacer desde 1969, muchos de los cuales se desarrollaban en forma de espectáculos de masas, desfiles en los que se sobre-emplean símbolos colectivos que denunciaba el salmantino ${ }^{19}$. Se podría aducir que esa crítica no se llevó a cabo por pura cronología: la reedición del libro de Marchán es de 1974, cuando el autor aun no se había topado directamente con la obra de Miralda ${ }^{20}$. Más sorprendente resulta que no se produjera después, una vez conoció la obra del catalán, ocurriendo exactamente lo contrario: la literatura posterior de Marchán ha admitido su complicidad ${ }^{21}$ con la obra del catalán.

Cirici también mostró reticencias. Escribiendo sobre el happening en 1976, advertía la crisis de un medio nacido al calor de las revueltas del 68: "Una cierta exigencia de rentabilidad ha cercenado los vuelos a la Luna, pero también ha sometido el fenómeno que estudiamos (el happening) al imperio de una cosificación, si no directa por lo menos en forma de films, videotapes, fotos, xerocopias y publicaciones con valor de intercambio"22. Cirici pudo prever que la multiplicidad de la obra de arte conceptual no conducía directamente a la negación de la mercancía sino a su expansión en nuevos formatos. Es útil recordar que las palabras de Cirici aparecieron en uno de los primeros estudios sobre el happening, el publicado con motivo del congreso sobre este formato que se desarrolló en Granollers en 1976 y al que asistieron estudiosos del tema a nivel internacional. Esta convocatoria se hizo a la sombra de dos happenings realizados en 1974 cuya comparación resulta especialmente interesante: el happening realizado por Eduardo Arranz y Rafael Bartolozzi bajo la dirección de Joan Illa Morel, JIM, el 23 de mayo y el realizado por Dalí el 19 de agosto.

Ambas actividades suponían un zambullido en lo festivo, aunque de modos muy diferentes. Del primer caso, realizado en las fiestas de la Ascensión, se conservan pocas fotografías, pero en todas ellas se subraya la participación del pueblo (se decía que participaron más de mil personas que llevaron pancartas pintadas y vestimentas coloridas además de un instrumento de su elección) hasta tal punto que queda diluido el papel de los artistas completamente mimetizados en el gentío ${ }^{23}$. En el segundo, todo se centraba en el protagonismo de la figura de Dalí que caminaba con un nutrido grupo de reporteros visuales para sacar imágenes del astro surrealista que luego pasaron a la película "Viaje al Alto Mongolia-Homenaje a Bertrand Russell" (Montes Bacquer, 1975). El im-

\footnotetext{
17 Marzo, 2015.

18 Marchán, 1994: 208. Le debo esta observación a Sonia Lombao, 2015: 45-46.

19 Marchán, 2008: 208. Para construir su argumento Marchán recurrió a Nuevos Ritos nuevos mitos de Gillo Dorfles, libro que analizaba el rito progresista y fascista. Dorfles, 1969: 17.

${ }^{20}$ El primer encuentro de Marchán con la obra de Miralda se produjo en París (1979). Marchán, 2002: 9.

21 Marchán, 2015: 13.

22 Cirici, 1978: 9.

23 Arranz y Bravo, 1982: 7-19.
} 

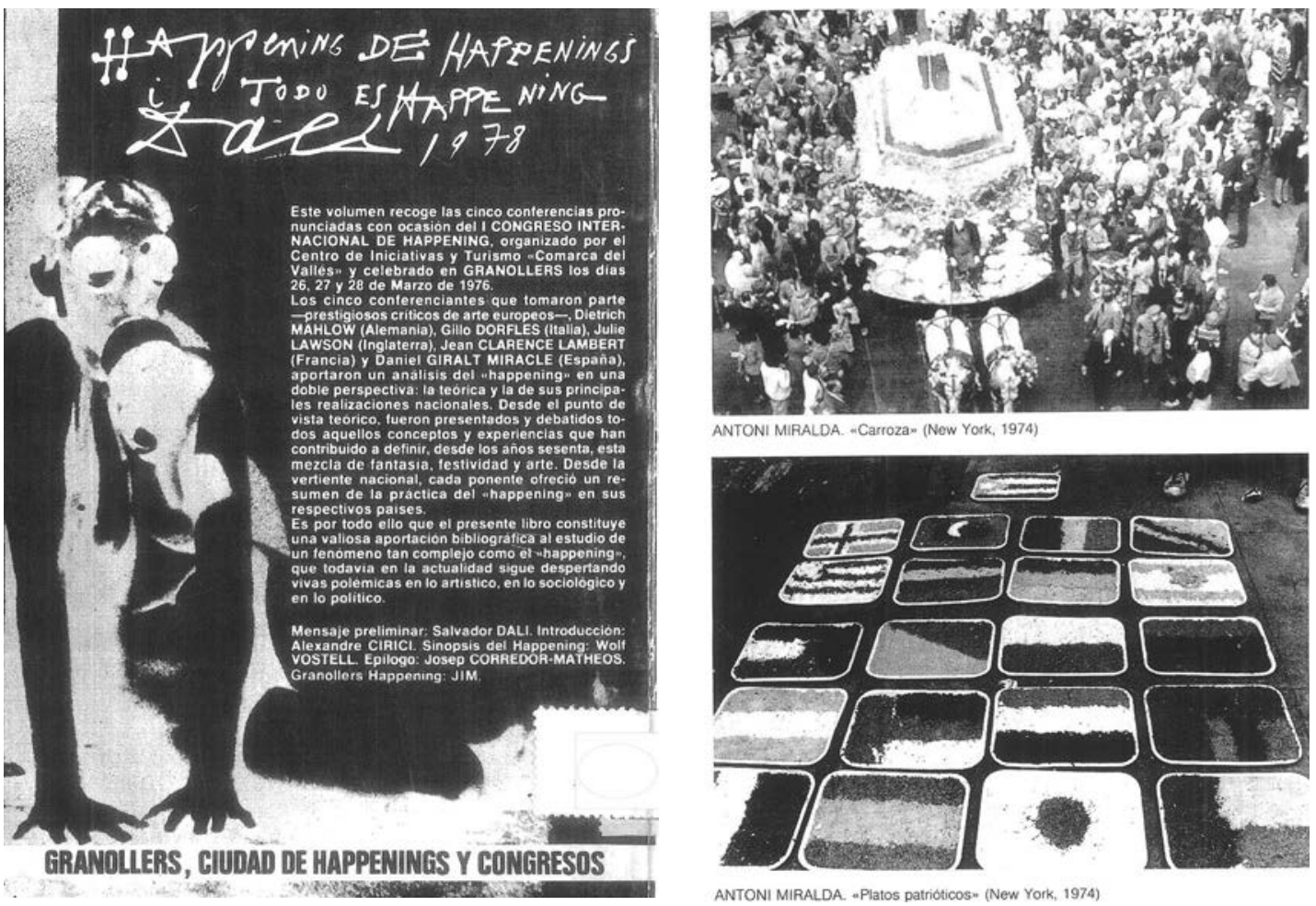

Figs. 1 y 2. Happening de happenings y todo es happening (1978).

pacto de este happening llegó incluso al No-Do ${ }^{24}$ que emitió las imágenes con comentarios que aclaraban las referencias al mundo del ritual religioso-mitológico que acompañaban al "celebrante".

En un país en el que el carnaval estuvo prohibido desde el final de la guerra hasta la muerte de Franco, el happening se plantea casi como una excusa cargada de modernidad y cosmopolitismo con la que recuperar soterradamente la fiesta en la calle ${ }^{25}$. Pero las formas en las que esto se llevó a cabo, al menos en Granollers, eran opuestas: en el happening de Bartolozzi y Arranz era el pueblo el único integrante de la propia festividad, sin protagonismos ni imágenes dominadas por ningún personaje capital; en el segundo, parecía hecho tan sólo para engrandecer a la personalidad del artista, Dalí, que concentraba todas las miradas. El contexto marcado por la contracultura pudo actualizar a Dalí gracias a este tipo de happenings olvidando su vínculo con la oficialidad franquista en favor de su juventud bohemia ${ }^{26}$; de hecho, se convirtió en fuente de inspiración para muchos jóvenes de Granollers — como el propio $\mathrm{JIM}^{27}$.

De entre las dos actitudes planteadas por estos happenings, la popular y la elitista, claramente triunfó la segunda. En 1975, JIM y otros compañeros montan el CIT, acrónimo de Centro de

${ }^{24}$ No-Do n. $^{\circ} 1651$ A $(2 / 9 / 1974)$.

${ }^{25}$ El carnaval fue la fiesta menos consentida por el franquismo; las asociaciones religiosas organizaron las fiestas que substituían al carnaval. Cuando el gobierno veía que algunas fiestas conseguían repercusión social intervenía económicamente para contralarlas. Escalera Reyes, 2003: 253-261.

${ }^{26}$ Se debe recordar que Dalí comentó en la prensa francesa que las últimas ejecuciones del dictador le parecían escasas.

27 Narcís Sellés ha retratado la compleja comprensión de Dalí en el contexto de la Transición en el entorno gironí. La Asamblea Democrática de Artistas de Girona (ADAG) vetó la presencia de Dalí en una exposición de homenaje a Carles Rahola (1978) por el apoyo del artista al Dictador. Sin embargo, incluso en ADAG, algunos artistas, como Damiá Escuder, tenían una posición ambivalente que les llevó a promover la construcción de un monumento daliniano en honor a Francesc Pujols en 1981. Sellés, 2017: 57 y 75. 
Iniciativas y Turismo de la Comarca del Vallés, empresa bajo la que se organizó el Congreso de Happenings en 1976, actividad que, contando con el apoyo del Ayuntamiento, quería emular el milagro económico alemán en el plano cultura ${ }^{28}$. No cabe duda de que la convocatoria perseguía colocar a Granollers en el mapa turístico y, para hacerlo, no dudó en recurrir a la atención que atraía Dalí. Reflejo de esto fue el slogan "Granollers, ciudad de happenings y congresos" acompañado por la firma de Dalí impresa en la contraportada del libro que reunía las participaciones del Congreso [fig. 1].

Entre los participantes en la publicación estaba Josep Corredor Matheos ${ }^{29}$ cuyo escrito, centrado en el vínculo entre happening y fiesta, reflejaba las ambigüedades que acompañaban a todas estas actividades. El texto de Corredor consistía, en líneas generales, en un recorrido antropológico con referencias que iban del homo-ludens de Huizinga, al Feast of Fools ${ }^{30}$ de Harvey Cox, teólogo esencial en la adaptación del cristianismo a la contracultura; pero más relevante aún es que las únicas imágenes que acompañaron al texto eran de obras de Miralda lo que directamente le convertía en máximo representante del nudo entre happening y festividad [fig. 2].

\section{Carnaval Miralda}

Un joven Miralda llega a París, atraído por su ambiente, en 1962 debiendo abandonarla episódicamente para cumplir con el servicio militar. Entre medias, trabajó como fotógrafo para la revista de moda Elle, teniendo aún tiempo para comenzar su obra más característica de estos años: los soldaditos, dibujados y de plástico, que inundaban todo espacio, clara metáfora de la obsesiva militarización por la que pasaba. Esta serie, Soldados saldados, desarrollada hasta 1973, debió llamar la atención del Nouveau Réalisme francés puesto que apelaba a la apropiación de lo real, recurso principal de muchos de los artistas franceses (evidente en Arman) según el crítico del grupo, Pierre Restany, autor de varios textos sobre el catalán.

La relación entre Restany y Miralda - así como con el llamado grupo de catalanes de París (Joan Rabascall, Jaume Xifra, Benett Roseell...) - , ha sido tomada como síntoma del cosmopolitismo del arte catalán impidiendo un acercamiento en profundidad al trabajo de este crítico sobre la obra de estos artistas ${ }^{31}$. Ha sido Kaira Cabañas quien con más rigor ha contextualizado el trabajo de Restany y su comprensión del realismo presente ya en el título del grupo de artistas con los que se le asocia. Según Cabañas, la noción de realismo que manejó Restany estaba muy alejada del materialismo dialéctico asociado al término. Al contrario, este modelo de directa apropiación de lo real ${ }^{32}$ se debe entender como un intento de desplazar el compromiso sartriano, dominante entonces en Francia, en favor de la aceptación de objetos producidos en masa indistinguibles de los objetos artísticos. Para Cabañas esta concepción supone el desvanecimiento del realismo como un debate estético y, por consiguiente, la aceptación acrítica de la realidad, en particular de los objetos surgidos de la industria que son apropiados sin considerar las relaciones sociales de producción que las alumbra. En nuestra opinión, los ceremoniales que Miralda organiza desde 1969 suponen el mejor ámbito en el que Restany pudo volcar su comprensión del realismo.

Los ceremoniales se inician en el seno de los artistas catalanes de París además de Dorotheé $\mathrm{Selz}^{33}$, artista de origen francés con la que Miralda desarrolló el arte comestible. El primer ceremonial, Memorial se realizó en la localidad francesa de Oise el día de los difuntos de 1969 por

${ }^{28}$ Barceló, Albert y Riobó, Carlos (dirs.): Happening de happenings y tot és happenings, 2010. En: "https://www. youtube.com/watch?v=hKYZsp8yOo8" [14 de agosto de 2018] (21'23”).

29 Corredor Matheos, 1978: 66-86.

30 Corredor Matheos, 1978: 74.

31 Parcerisas, 2007: 373.

32 El realismo defendido por Restany era tan desprejuiciado que le llevó a rechazar el empirismo científico al implicar cierto tipo de análisis de lo percibido. Cabañas, 2013: 16.

33 Parcerisas, 2007: 191. 

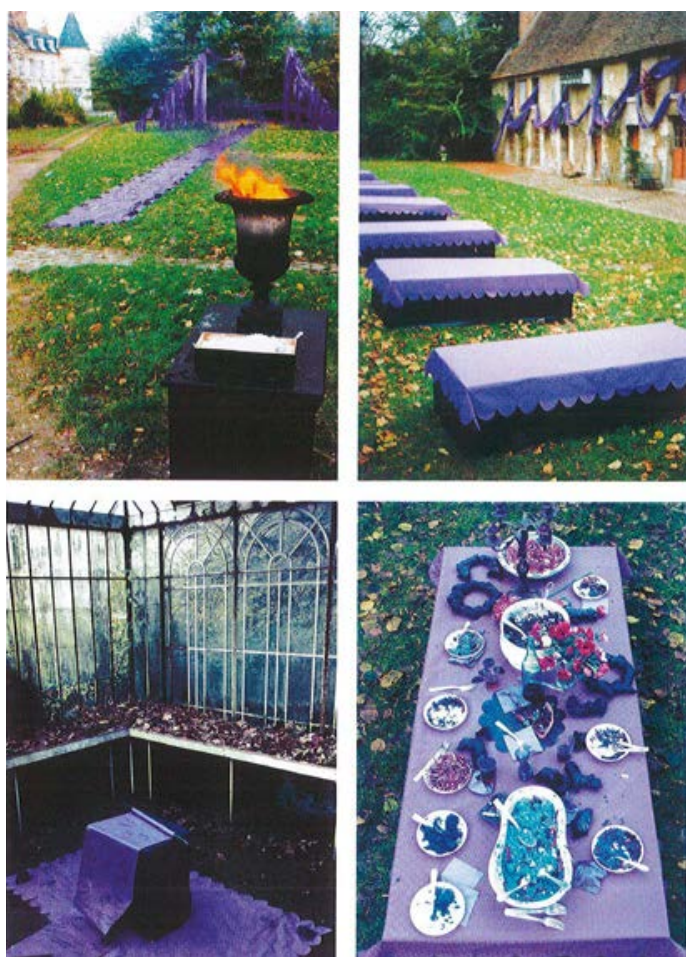

Fig. 3. Antoni Miralda, Joan Rabascall, Dorotheé Selz y Jaume Xifra, Memorial, 1969.

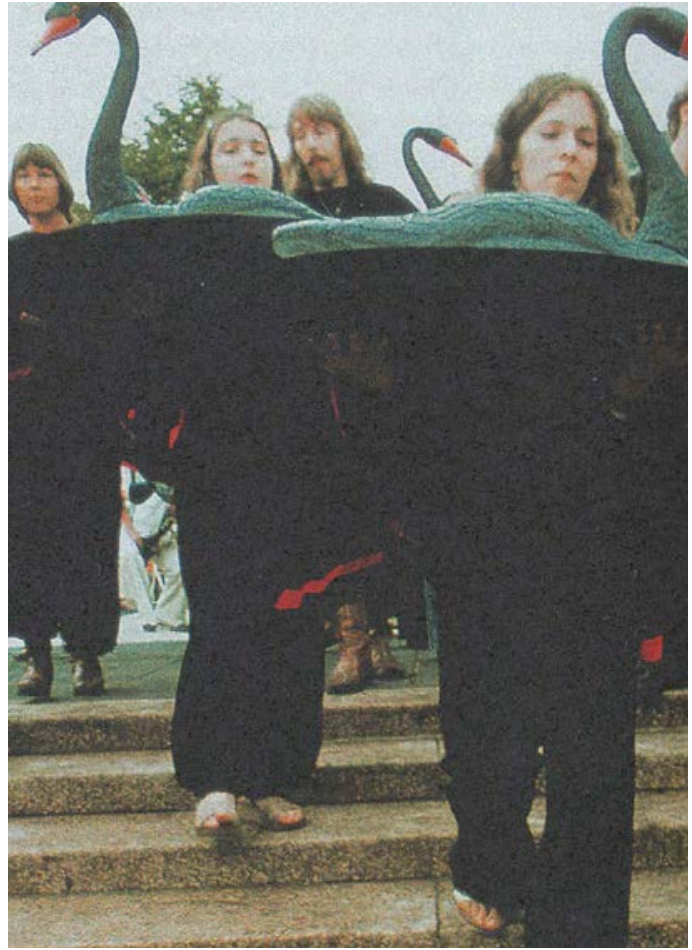

Fig. 4. Antoni Miralda, Fiesta en honor a Leda, 1977.

lo que la obra tiene un marcado carácter mortuorio: pasteles negros sobre sobre mesas-tumba también de color negro, abundancia del color malva tanto en los objetos como en la comida, coronas de flores, pasteles negros...34.

La obra sucedía en diferentes escenarios y acciones con un carácter muy marcado cercano al ritual religioso e incluso a una procesión. Aparte del sentido funerario, parece haber en el conjunto una utilización extremadamente literal de los códigos y símbolos empleados: el día de los difuntos marca el tono del ceremonial aportando el carácter funerario que impregna el constante uso de los colores negro, símbolo occidental del luto, y morado, color característico de la cuaresma que comienza con el recuerdo de la ceniza como origen y destino del cuerpo humano. Lo que se está produciendo es una utilización literal del régimen de significación y simbolización tradicional, con especial atención a la tradición católica que empapa todo el rito [fig. 3].

La simbología de los colores concentra capital importancia en la mayoría de los ceremoniales realizados en los años setenta: la Fiesta en blanco, realizado también en Oise (1970), tomaba como motivo una boda que explicaba la invasión de ese color; en 1971 Miralda realizó el Ritual en cuatro colores, una procesión de participantes que portaban túnicas y máscaras rojas, verdes o amarillas que culminaba con comida de esos mismos colores que, mezclados en el estómago de los asistentes, producirían el cuarto color blanco, como sucede con la superposición de luz de esos tres colores.

La utilización de lo real en Miralda tiene que ver más con la dimensión simbólica que con el ready-made duchampiano: las fechas tienen el mismo sentido que en calendario normal y los colores poseen la misma dimensión simbólica que en la vida real, todo lo cual es reconocido por el propio Restany cuando describe Fiesta en Blanco como una "yuxtaposición de

\footnotetext{
${ }^{34}$ AAVV, 2010: 113.
} 
símbolos relacionados con el blanco: pureza, virginidad, boda, primavera, alabastro, tiza, lirio, vino Blanc de Blancs, almacenes la Grande Maison Blanc" 35 . El color, concepto estructural en el discurso histórico-artístico desde el Renacimiento, se convierte en un elemento de capital importancia impregnándolo todo, del título a la comida. Y es en la comida donde el color alcanza su cualidad simbólica más perfecta al representar lo artístico en sí mismo ya que es el aditivo que legitima la transformación de la comida en nuevo material del arte ${ }^{36}$. Y la comida, así convertida en arte, separa forma de función ${ }^{37}$, estética de uso provocando su entrada en el ámbito del desinterés kantiano.

Uno de los ejemplos donde mejor se pueden ver las repercusiones de la no intervención de Miralda en los códigos simbólicos es Fiesta en honor a Leda, desarrollada en la Documenta (1977) y consistente en un recorrido preconcebido por la ciudad de Kassel por parte de un numeroso grupo de participantes ataviados con túnica negra y roja. La procesión tenía un preciso recorrido con diferentes paradas: exteriores de las salas del teatro local, Palacio de Mármol donde se dispuso una bañera con sangre en referencia a la II Guerra Mundial - este edificio fue uno de los pocos que quedó en pie tras los bombardeos aliados. En el jardín del Palacio, la comitiva cogía reproducciones en plástico de cisnes negros con transistores en su interior que emitían reclamos y sonidos de sirenas que alertaban un inminente bombardeo, que eran depositados en un lago que cruzaban con un mecanismo [fig. 4)].

El carácter de procesión disciplinada quedaba potenciado por un régimen semiótico increíblemente estable en el que nuevamente cualquier significado propio de la vida real quedaba sin trastocar: el cisne aludía al mito clásico de la unión de Leda y Zeus; el negro, a la muerte; el rojo, la sangre. La obra en su conjunto manejaba un orden de significados que, al no ser subvertidos, se acoplaban perfectamente al lugar que acogía la exposición — es más, el Palacio de Mármol poseía ya una escultura de Leda. El sistema de significados negaba una comprensión del lugar que rechazara lo ya presente.

En 1996, el crítico François Burkhardt eligió esta misma obra para plantear las últimas consecuencias de la literalidad simbólica de Miralda - recurso que compartía con Joseph Beuys- y que el crítico entendía como un "lenguaje refinado que empleaba el dramatismo de los símbolos populares para poder significar en diferentes capas sociales" 38 . Dicho tropo le permitía llegar a la conclusión de que Miralda empleaba un lenguaje abierto y compartido que evitaba exclusiones de cualquier tipo, es decir, un lenguaje universal epítome de la comunicación naturalizada por todo ser humano, algo ya cuestionado entonces desde la deconstrucción.

La aportación de Burkhardt es relevante ya que revela cómo fue entendida la obra de Miralda en los años noventa, década del prodigioso "fin de la historia". Burkhardt introducía la nueva utilidad del arte en el contexto posthistórico:

El arte ha dejado de existir en tanto que fenómeno específico, ha sido superado por una estetización de la existencia propia de la cultura postindustrial. Liberados de una teoría de la discontinuidad basada en el hecho de que lo nuevo aparece como un factor destructivo y como una interrupción del desarrollo histórico, estos artistas ya no esperan que el arte sorprenda en una sociedad futura profundamente transformada, sino que plantean la experiencia artística como un fenómeno estético de integración en la vida cotidiana. Tienen en cuenta el impacto de los medios de comunicación, la distribución de la información, la importante función de la diversión, de la incitación al placer siempre aplicado a criterios de belleza, sofisticación y refinamiento técnico, criterios propios del espectáculo y de la animación de los sentidos ${ }^{39}$.

5 Restany, 1982: 13.

36 "Por medio del concepto de coloración de los alimentos ordinarios y de la comida coloreada, transformada ipsofacto en ritual de la fiesta, Antoni Miralda y Dorotheé Selz inician su auténtica carrera en la larga historia del arte comestible". Restany, 1982: 12.

37 Labrador (sin publicar).

38 Burkhardt, 1995: 14-15.

39 Burkhardt, 1995: 14-15. 


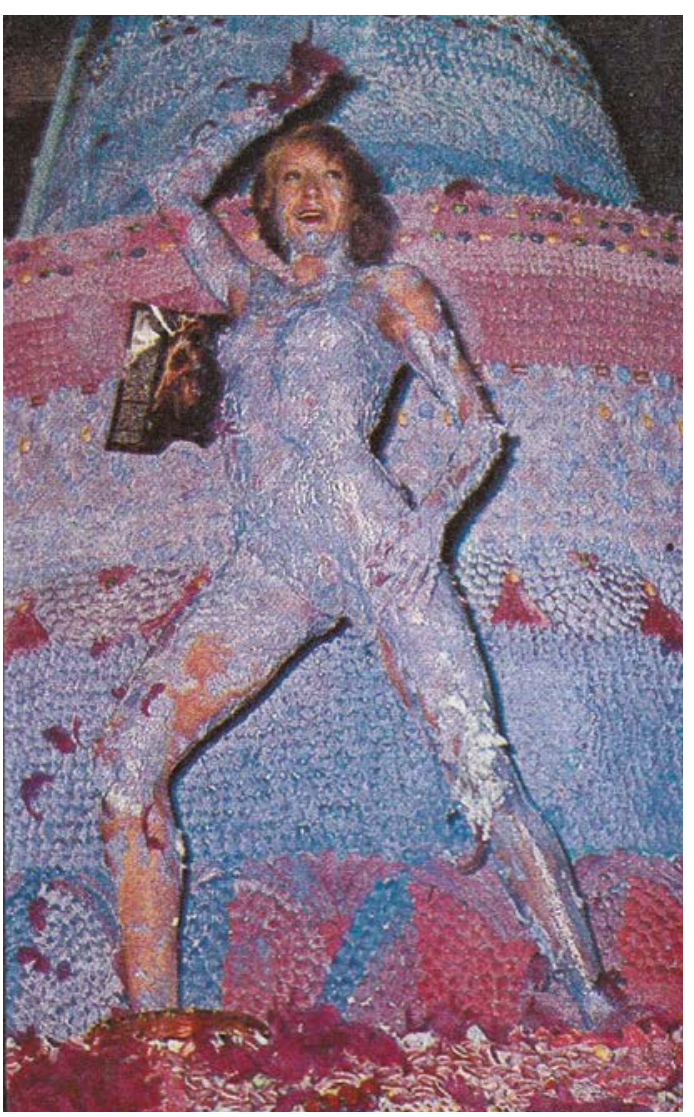

Fig. 5. Christa Lem en Yes, n. ${ }^{\circ}$ 1, 1977.

Como rezaba el título del ensayo: "Miralda: el arte de saber alcanzar el consenso público".

El empleo que Burkhardt hace de la palabra "consenso" revela un ámbito de significado extraño en el contexto del arte de acción toda vez que dicho concepto ha adquirido una serie de implicaciones íntimamente ligadas a la transición española. La palabra "consenso" se refiere habitualmente a la reconciliación tras la muerte de Franco, ejemplificada en los Pactos de la Moncloa (1977). Hasta fechas muy recientes este proceso se ha entendido como el triunfo político ejemplar del proceso democratizador por lo que ocupa un puesto clave en el relato idealizado de la Transición política. Sin embargo, hoy este relato está completamente roto y ahora bajo el término consenso se esconden la pérdida de ilusiones y proyectos renovadores desvanecidos al poco de la muerte del dictador ${ }^{40}$. El binomio happening y consenso provoca extrañeza ya que este medio artístico sigue siendo entendido, a nuestro entender, como esencial vehículo de expresión de la rebeldía propia de los sesenta y setenta $^{41}$. En el caso de Miralda, esta extrañeza es incluso mayor teniendo en cuenta su participación con Selz en el Congreso Internacional de Diseño (ICSID) de Ibiza (1971), donde realizó un Ritual multicolor que adoptó dimensiones cuasi-orgiásticas, razón por la que ha sido incluida en varias exposiciones centradas en las prácticas subversivas (WKV, Stuttgart, 2008) en diferentes latitudes ${ }^{42}$.

Fiesta en honor a Leda no es la única obra de Miralda que acogía fenómenos característicos de la Transición. En 1976, Miralda fue invitado por la revista erótica del Grupo Zeta Yes para organizar un happening con el que celebrar la salida de su primer número surgido al calor del aperturismo moral [fig. 5]. Resultaría difícil entender este boom erótico sin mencionar el fenómeno local del cine del destape característico de las últimas décadas de la dictadura, donde se daba rienda suelta al placer visual hasta entonces ajeno a la vida pública y cultural ${ }^{43}$. Por otro lado, tras la muerte de Franco, se produce en España una situación única como es la construcción prácticamente desde cero de la cultura visual erótica del país, lo cual conllevó fenómenos muy particulares como la clasificación de películas " $\mathrm{S}$ " - a diferencia de la internacional categoría "X"-, en la cual no sólo se acogía lo erótico sino cualquier película controvertida (p.e. "El crimen de Cuenca" de Pilar Miró). El limbo que proporcionaba este género abrió la puerta a la experimentación en algunas películas de contenido erótico que no se agotaba en el puro placer visual ${ }^{44}$.

40 El ejemplo más evidente es Wilhelmi, 2016.

${ }^{41}$ Marzo, 2015.

42 Que otras muchas obras de Miralda no llevaran a la exaltación orgiástica demuestra que lo que ocurrió en el ICSID se debió a sus participantes y no a la obra de Miralda.

43 Viadero piensa que la ruptura con la moral nacional-católica del destape también reafirmó modelos de relación propios del franquismo (Viadero, 2016: 338). Aún así, no se debe subestimar el erotismo que, por encima del contenido y la ideología, era con seguridad la principal razón de algunos taquillazos.

${ }^{44}$ Kowalski, 2004: 188-208. 
Christa Leem fue una de las actrices que surgieron en esta época y, aunque solo hacía pequeños papeles encarnando a la nueva mujer postdictatorial de insaciable voracidad sexual, su fama alcanzó nivel nacional. Cuando Miralda trabajó con ella en la presentación de Yes, Leem estaba culturalmente connotada hasta tal punto que un grupo de feministas se manifestaron en el exterior del local que acogía la fiesta denunciando la utilización del cuerpo femenino ${ }^{45}$.

Lo festivo, la celebración y la fiesta han sido aspectos muy presentes en la obra de Miralda, lo que ha llevado a emplear la noción de carnaval para entender su obra ${ }^{46}$. Este concepto, de claro origen bajtiano, ha sido un recurso teórico común en el análisis de obras de arte que, de una u otra manera, hacían referencia a la festividad transgresora o a cualquier tipo de celebración. Ello ha derivado en una simplificación de la obra del lingüista ruso a la que se recurre siempre que, aunque mínima, haya una referencia a la fiesta. Todavía está por investigar la recepción en España de su famoso ensayo sobre el carnaval durante la Edad Media y el primer Renacimiento, donde fundamenta gran parte de sus teorías sobre este fenómeno cultural ${ }^{47}$. A pesar de ello, sigue siendo relevante volver al famoso ensayo de Bajtín para ver cómo el carnaval queda representado.

Una atenta lectura de esta fuente nos ofrece una visión radical del entretenimiento que nunca vincularíamos con lo que hoy en día entenderíamos por fiesta: el carnaval bajtiano supone una auténtica amenaza a las normas morales, así como al respeto que enmascara las relaciones de clase. Es tan radical la inversión que se produce en Bajtín que llega a denominar "lógica de las cosas al revés" al principio dominante en el carnaval, según el cual toda jerarquía y norma es invertida. En otro apartado, Bajtín se refiere a dicha desjerarquización con la expresión "realismo grotesco", en donde lo "grotesco" adquiere dimensiones escatológicas ${ }^{48}$. Es posible que el romanticismo que en ocasiones parece vislumbrarse en Bajtín fuera lo que en definitiva nunca le llevara entender el carnaval como un fenómeno de su presente denunciando toda interpretación que se saliera de los límites cronológicos tardomedievales. Y al respecto, es relevante señalar cómo vio en el mundo artístico de su contemporaneidad, que llamaba bohemia, el contexto que con mayor ahínco perseguía una degradada ${ }^{49}$ imagen del carnaval.

Otro ejemplo de Miralda, también de mediados de los años setenta, puede ser útil para ver cómo se produce la particular inversión de lo festivo, lo carnavalesco y la pérdida de jerarquías en su obra. Se trata de Situació-Color, realizada junto con Jaume Xifra en 1976 en la vivienda del coleccionista Josep Sunyol en las Escales Park, el famoso edificio del arquitecto Josep Lluis Sert. La obra consistía en un recorrido de los invitados por el edificio y por las tres plantas que componían la vivienda. Cada una de estas plantas se asoció a un color determinado (malva, naranja y verde) de tal modo que según pasaban los invitados se les "condecoraba" con una capa de ese determinado color; la comida respondía igualmente a estos patrones de diferentes colores y la recepción a la vivienda contaba con la actuación en vivo de Jaume Sisa ${ }^{50}$. El recorrido culminaba con unas copas en la terraza, pero a lo largo de éste se dispuso una particular escenificación del trabajo doméstico: en el patio de luces se podía contemplar desde un piso superior, es

\footnotetext{
45 Estella y Rosón, 2018.
}

${ }^{46}$ Como queda claro en la siguiente lectura de la obra de Miralda: “... a través del elogio y el insulto cortés pero incisivo, el artista reescribe y reinventa el lenguaje del mercado (la historia como capitalismo) cuando carnavaliza — cuando trasviste, por así decirlo - el desfile tradicional y jerárquico en pasacalle festivo". Novero, 2010: 60.

${ }^{47}$ La teoría literaria ha determinado la recepción de Bajtín en España a diferencia de otras latitudes donde la lectura se ha realizado desde otras perspectivas. Bubnova, 2008: 48.

48 Un fragmento presenta la intensidad de lo grotesco en Bajtin: "Los ejemplos que acabamos de citar demuestran que el arrojar excrementos y rociar con orinas son actos degradantes tradicionales, conocidos no sólo por el realismo grotesco sino también por la Antigüedad. Su significación era fácilmente comprendida. Existe en casi todas las lenguas la expresión, 'me cago en ti' (o giros similares, como escupir en la cara). En la época de Rebelais la expresión 'mierda para ti', era muy corriente". Bajtin, 2003: 118-119.

49 Bajtín, 2018: 28.

50 Sisa interpretaba "Qualsevol nit pot sortir el sol" (1975), tema del pop catalán que narra la llegada de personajes fantásticos a una casa. La canción fue censurada en el festival Canet Rock (1975), siendo hoy considerada una canción crítica. En Situació-color el contenido de la canción parecía ilustrar la fiesta sin abordar crítica a la alta burguesía, necesaria según la interpretación carnavalesca. 


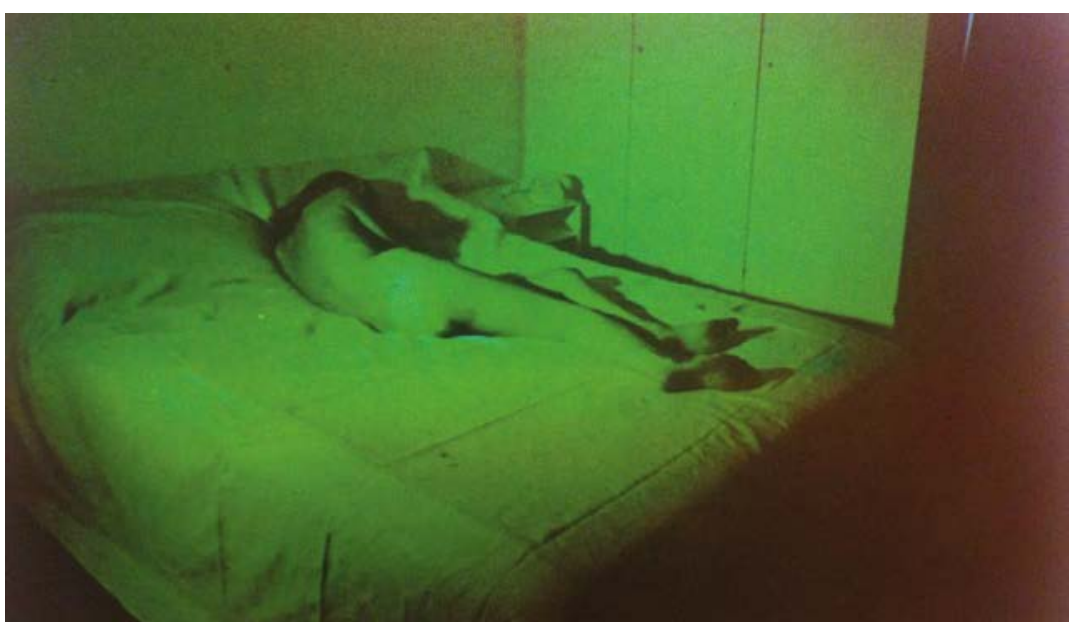

Fig. 6. Situació color. París: Galería Vandrés, 1976 (sin paginar).
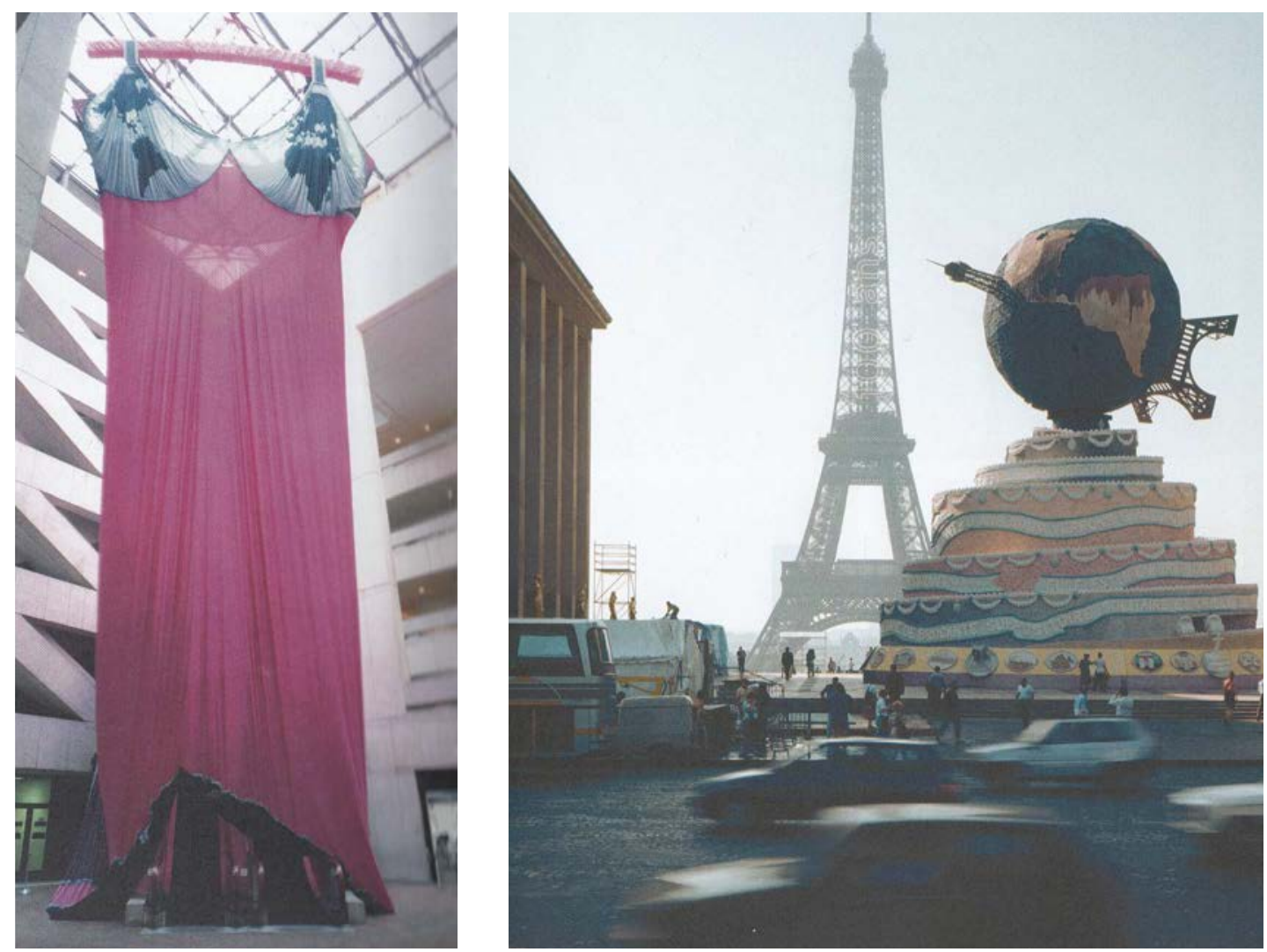

Figs. 7 y 8. Honeymoon project, 1986-1992.

decir, desde una posición de claro dominio, al colchonero haciendo su trabajo ${ }^{51}$, o lo que es lo mismo vareando la lana; en el interior de la vivienda, un camarero vestido de gala cortaba el pan mientras una asistenta planchaba la sábana que después firmarían los invitados; en una habitación, otra asistenta dormía desnuda encima de la cama, siendo objeto del placer visual de los

51 Sin autor, 1976: (sin paginar). 
invitados que la podían espiar a través de la puerta entreabierta [fig. 6)]. La descripción revela claramente que la inversión carnavalesca estaba completamente ausente en esta obra; más bien, al contrario: a lo largo de toda la fiesta se producía una reafirmación de las relaciones de clase dominantes en la vida real: el servicio desarrollaba aquello que le define - trabajar para los demás - y los invitados hacían su papel — disfrutar de la música, de la comida, las copas ... el servicio. Es decir, más que las teorías de Bajtín y la subversión del mundo al revés, son los planteamientos de la directa apropiación de lo real de Restany lo que Miralda había recreado.

Concluimos este estudio planteando la necesidad de revisión del arte de acción y su dimensión resistente: no todo happening es por serlo crítico o reivindicativo; en ocasiones consolida estereotipos dominantes. La revisión historiográfica debería partir de ese hecho ineludible más aún hoy cuando el giro performativo ha antecedido el auge de modos de intercambio económico inmateriales. En cuanto a Miralda, el tiempo acentuó la reafirmación de lo ya existente presente en su obra: entre 1986 y 1992 desarrolló un ambicioso proyecto de matrimonio entre la Estatua de la Libertad y la de Cristóbal Colón coincidiendo con las Olimpiadas de Barcelona, proyecto que implicó la celebración de varias fiestas en las que se presentaba el ajuar nupcial [figs. 7 y 8]. El proyecto se simultaneó a la reforma urbana que transformó a Barcelona de ciudad industrial a postindustrial antesala de la ciudad creativa; proceso acompañado de la construcción oficial de la memoria intencionadamente plagada de ominosos silencios ${ }^{52}$. A ello contribuyó Miralda con su acción, un ritual que destaca por su ortodoxia litúrgica evidente en un matrimonio imposible ni siquiera simbólicamente, así como en la concentración en el ajuar cuando este no era más que un recuerdo del pasado al menos en las grandes urbes.

\section{BIBLIOGRAFÍA}

AA.VV. (2002): Sabores y lenguas. Madrid: Fundación ICO.

AA.VV. (2010): De gustibus non disputandum. Madrid: Museo Reina Sofía.

Arranz-Bravo, Eduardo y Bartolozzi, Rafael (1982): Arranz-Bravo, Bartolozzi y su laberinto, CUPSA, Madrid.

Bajtín, Mijail (2003): La cultura popular en la edad media. El contexto de François Rebelais. Madrid: Alianza editorial.

Bajtín, Mijaíl (2018): “Un mundo carnavalesco: de la carnavalización de la vida y la carnavalización literaria. En AA.VV. Vida de carnaval. De máscaras, parodias, literatura y carnavalización. Madrid: Libros corrientes, pp. 9-49.

Balsach, María Josep (2001): Del Nuagisme a la crisi de l'art informal. Sabadell: Museu d'art de Sabadell.

Balsach, María Josep (2013): "Vladimir Slepian i els orígens de la pintura d'acció a Catalunya (1959-1960)". En: Quadern de les idees, les arts $i$ les letres 192, pp. 21-23.

Burkhardt, François (1995): "Miralda: el arte de saber alcanzar el consenso público”. En: AA.VV.: Miralda. Obres: 19651995. Valencia: IVAM, pp.14-15.

Cabañas, Kaira (2013): The myth of the new realism. Art and the performative in postwar France. Yale: Yale Univ. Press.

Cirici, Alexandre (1963): "Nou realisme a catalunya". En: Serra d'Or, 10, pp. 37-39.

Cirici, Alexandre (1970): L'art catalác ontemporani. Barcelona: Edicions 62.

Cirici, Alexandre (1957): “L'art vulgar”. En: Cap d'any Raixa, vol. 2. Palma de Mallorca: Moll, pp. 105-112.

Cirici, Alexandre (1978): "Happening e historia". En: Happening de happenings y todo es happening. Granollers: Colección Granollers Happening, p. 9.

Corbeira, Darío / Expósito, Marcelo (20004): “Entrevista a Simón Marchán”. En: Carrillo, Jesús / Estella Ignacio y García Merás, Lydia (eds.): Desacuerdos 1, Sobre arte políticas y esfera pública en el Estado español, Barcelona: MACBA, p. 140-144.

Corredor Matheos, Josep (1978): “Jugar, pensar, vivir”. En: Happening de happenings y todo es happening, Granollers: Colección Granollers Happening, pp. 66-86.

Crespo, Ángel (1965): “Sobre la insularidad del arte español”. En: Aulas: Educación y cultura, 23, pp. 36-37.

De Martino, Ernesto (2008): El folklore progresivo y otros ensayos. Barcelona: UAB.

Delgado, Manuel (2007): La ciudad mentirosa. Fraude y miseria del modelo Barcelona. Madrid: Catarata.

Dorfles, Gillo (1969): Nuevos mitos, nuevos ritos. Barcelona: Lumen.

Escalera Reyes, Javier (2003): "El franquismo y la fiesta. Régimen político, transformaciones sociales y sociabilidad festiva en la España de franco". En: Uría González, Jorge (coord.): La cultura popular en la España contemporáneo: doce estudios. Madrid: Biblioteca Nueva, pp. 253-261.

\footnotetext{
52 Delgado, 2007: 99.
} 
Estella, Iñaki / Rosón, María (2018): "El cuerpo en la transición: sexualidad, feminismo y el striptease de Christa Leem”. En: Albarrán, Juan (ed.), Arte y Transición 2. Madrid: Brumaria, pp. 133-156.

Expósito, Marcelo: “1969- ... Hipótesis de ruptura para una historia política del arte en el Estado español”. En: Carrillo, Jesús, Estella Ignacio y García Merás, Lydia (eds.): Desacuerdos 1, Sobre arte políticas y esfera pública en el Estado español, Barcelona: MACBA, p. 128.

Garbayo, Maite (2016): Cuerpos que aparecen. Performance y feminismos en el tardofranquismo. Bilbao: Consonni.

Kowalski, Daniel (2004): "Rated S. Softcore pornography and the Spanish Transition to Democracy, 1977-1982". En: Lázaro Rebollo, Antonio y Willis, Andrew (eds.): Spanish Popular Cinema. Manchester: Manchester Univ. Press, pp. 188-208.

Labrador, Germán (sin publicar): "La marea caníbal. La lógica cultural de la temporalidad de crisis en España, entre revolución, biopolítica, hambre y memoria".

Lombao, Sonia (2015): Arte de acción en Cataluña. Jordi Benito y su contexto (tesis doctoral inédita). Barcelona: UBA.

Marchán, Simón (1983): “La penetración del pop en el arte español”. En: Goya, 174, pp. 360-370.

Marchán, Simón (1991): “Los años setenta entre los nuevos comportamientos artísticos y la recuperación pictórica”. En: 23 artistas, Madrid, años 70. Madrid: Sala de Exposiciones de la Comunidad de Madrid, pp. 37-59.

Marchán, Simón (1994): Del arte objetual al arte de concepto. Madrid: Akal.

Marzo, Jorge Luis (2015): “Arte de acción y su emplazamiento en el relato artístico de los ochenta y los noventa". En: Albarán, Juan y Estella, Iñaki (eds.): Llámalo performance. Arte disciplina y recepción. Madrid: Brumaria, pp. 269-303.

Novero, Cecilia (2010): "Miralda: volver las tornas". En: AA.VV.: De gustibus non disputandum. Madrid: Museo Reina Sofía, pp. 59-70.

Parcerisas, Pilar (2007): Conceptualismos poéticos, políticos y periféricos. Madrid: Akal.

Restany, Pierre (1982): Miralda Une vie d'artiste. Barcelona: Ambit.

Romero, Pedro G. (2007): “Actores, situaciones, desenlaces. La máquina teatral y el teatro: escenas subalternas en el Estado español”. En: AA.VV.: Un teatro sin teatro, Barcelona: MACBA, pp. 46-51.

Sellés, Narcís (2007): "Pierre Restany i Alexandre Cirici. Dos critics de l'art del seu temps". En: Miramar, 2, pp. 54-60.

Sellés, Narcís (2017): Assemblea Democràtica d'Artistes de Girona (ADAG). Autoorganització, lluita simbòlica i pàctica social, 1976-1978. Girona: Museu d'Art de Girona.

Sin autor (1976): Situació color. París: Galería Vandrés.

Urbulú, Claudia (2015): Los catalanes de París. Un análisis estético. Barcelona: Dyckinson.

Viadero, Gabriela (2016): El cine al servicio de la nación. Madrid: Marcial Pons.

Wilhelmi, Guillermo (2016): Romper el consenso. La izquierda radical en la transición española. Madrid: Siglo XXI.

Fecha de recepción: 10-IX-2018

Fecha de aceptación: 11-II-2019 